\title{
Senior officer and recruiter views on "big topics" in policing for new recruits
}

Hina Kalyal,* Hillary Peladeau, ${ }^{*}$ and Laura Huey*

\begin{abstract}
Along with a focus on adopting more proactive approaches due to the changing nature of crime, police organizations today are also faced with the task of attracting and retaining a dynamic and flexible work force. The present study, based on semi-structured interviews with 12 recruiters and 21 senior police officers from police agencies across Ontario, seeks to determine whether these officers find the knowledge of new policing models useful for the professional development of incoming recruits. Despite the exploratory nature of the study, the results highlight the importance of the knowledge of "big topics" in policing prior to joining the service. Not only will such knowledge be useful for future recruits in developing a clear understanding of the challenges and realities of modern policing, but it will also lead to time and cost saving in terms of training and development.
\end{abstract}

Key Words Proactive policing; future trends; work expectations; training costs

Journal of CSWB. 2017 Dec;2(3):112-115

www.journalcswb.ca

\section{INTRODUCTION}

Owing to the increasing complexity of issues within the policing landscape today, the current focus of police work is shifting from traditional reactive approaches to the development of more proactive, upstream solutions. In view of such changes, an understanding of the 'big topics' in policing - that is, those strategies seen through rigorous trials to enhance the efficiency and effectiveness of police services-may help prepare new recruits entering service. What do we mean by 'big topics'? We have identified three ${ }^{1}$ of the most well-known within contemporary policing circles: 1) Intelligence-led policing (ILP), which relies on criminal intelligence and data analysis to manage risks within the community; 2) Problem-oriented policing (POP), an approach in which police develop innovative, local responses to specific community safety and other problems within a local area, and; 3) Evidence-based policing (EBP), which promotes the use of research to inform police decision making.

It has been argued that each of these approaches, singly and in combination, has the potential to assist police agencies in making the transition from reactive to proactive policing. However, each also requires some level of working knowledge of the relevant concepts, methods, roles, and realities entailed. For most police agencies, which are already struggling with increasing training demands, pre-entry knowledge of these 'big topics' might be useful. Rather than simply accept this proposition, we have instead put it to the test. The present paper, which is part of a larger study on the assessment of educational needs for new police recruits, is exploratory in nature and its purpose is to determine whether senior police officers and recruiters believe that a prior knowledge of the big topics in policing through education, can prove useful for incoming police recruits.

\section{METHODS}

The present study draws upon data collected for a larger study of educational requirements for incoming police recruits. Using non-probability sampling, we emailed police recruiters and senior officers from all the municipal and provincial police services in Ontario $(n=58)$. A total of thirty-three $(n=$ 33) officers were interviewed, including twelve $(n=12)$ police recruiters and twenty-one $(n=21)$ senior officers (Inspector and above) from eighteen $(\mathrm{n}=18)$ services. Interviews were based on a semi-structured guide with questions related to desirable qualities of future recruits, tools for competency assessment, general views on police education, and opinions on the quality of current higher education programs. This paper is based on the question: "Do you think it is important for the incoming recruits to have some idea of the big topics in policing such as problem-oriented policing, intelligenceled policing, and evidence based policing?" To answer this question, we employed Braun and Clarke's (2006) thematic

\footnotetext{
We did not include community policing under the umbrella of 'big topics' because it has been a staple of policing practice within most communities since the late 1980 s and we wanted to focus on more recent innovations.
} 
analysis approach, using, first, open coding to develop an initial set of themes, and then focused coding to narrow themes and connect them to relevant sub-themes.

\section{RESULTS}

Analysis of the data revealed two main themes related to the usefulness of knowledge of the big topics in policing at the pre-recruit level. Both of these are presented below.

\section{Understanding Future Trends and Managing Expectations}

The majority of recruiters $(n=11)$ and senior officers $(n=19)$ interviewed considered acquiring pre-recruitment education related to evidence-based, intelligence-led, and problemoriented models to be extremely important, as they saw these models as reflecting the future of policing. Senior officers also believed that the ability to embrace change and value new ideas should begin prior to joining the service, and therefore, pre-recruit education that focuses on the future of policing was considered important. Exposure to such ideas would enable future officers to handle responsibility and future challenges. For example:

"We are giving them the 'Why's' and we're giving them the 'Here's the possibilities'. So, they see that this is not just about arriving here and being a great recruit, or getting ready for the promotional system. This is actually about doing your job every single day."

Further, one senior officer admitted being overwhelmed by the new developments in police management when he joined the organization and believed that pre-recruit education on these topics would help develop best practices that reduce redundancies and duplication of resources. Similar sentiments were shared by other officers regarding the rapidly occurring changes in policing and the importance of developing the capability for continuous learning. For instance, one stated, "I think those [big ideas] would be absolutely key to their learning ... and I think those topics would have to be adapted almost annually or every couple of years to stay current because the world is changing faster than we can adapt to something."

Given the complex environment within which police officers must work today, it was also felt that modern recruits must be equipped with the education to operate at a global level and be aware of the issues affecting not only their immediate environment, but also those issues that cross borders:

"We want them to keep in-tune with issues that affect policing, because issues that affect the global organization are going to affect them and we want all of our individual parts to be aware and be able to respond to the external pressures that are put on us."

While most officers $(n=30)$ endorsed prior education related to the 'big topics' of policing, not everyone was convinced of the benefits. A few of the recruiters and senior officers $(n=3)$ believed that these were simply trends that would fade over time. One such interviewee noted, "You fluctuate from those types of catch-phrase policing, and it changes every ten years or so." Another expressed concern about justifying the use of funds for such practices and believed that they were simply trends driven by whoever was in power. The same officer seemed convinced that a knowledge of the 'big topics' in policing was deemed more suitable for senior-level officers than frontline officers, who he felt would not have a chance to apply such ideas until later in their careers. Officers in this group also believed that such specialized education could be imparted at the Ontario Police College and was not necessarily useful at the pre-recruit level.

Besides helping develop an understanding of current and future directions of policing, the 'big topics' also create a realistic picture regarding job related expectations. A significant number of senior officers $(n=12)$ and recruiters $(n=$ 5) agreed that one of the greatest benefits of pre-recruitment education on the 'big topics' would be the development of a clearer understanding of the realities of police work. One senior officer commented how policing was very different in practice, observing:

"It's not like it is on TV. It's not solving a case in an hour. It's not driving the car fast and arresting people, like it really isn't. That's the fun stuff and we all love to do that, but it's $20 \%$ of your work... so having an understanding of community based policing, intelligence-led policing, general community relations generally sets somebody up more for success coming into it because it's not necessarily going to be every day action packed to the end."

A recruiter considered it beneficial for the police departments to hire candidates who were aware of the demands of the profession, and remarked: "That's a great big boon for us because then, generally speaking, there's a match between our candidate... and our future employee as opposed to a lot of dissatisfaction across the page." Another expressed his support for recruits to have stronger educational backgrounds, in general, as this would prepare them for the constantly changing demands of policing, leading to greater job satisfaction and effectiveness. A senior officer shared the challenges experienced at the beginning of his career and stressed the need for pre-recruitment education and exposure to the latest developments in the field would help advance their careers.

Both recruiters and senior officers agreed that knowledge and appreciation of the big topics in policing would be a bonus to help develop a strong foundation for understanding the demands of police work from a corporate standpoint, as well as developing tactical plans. They believed that looking at the bigger picture and avoiding tunnel vision was imperative for effective policing. One of the senior officers strongly supported recruit education in the 'big topics' to encourage new officers to base their ideas on evidence from research, as such practices are being increasingly appreciated by police organizations today:

“... from a recruit perspective, understanding that when you make a decision, or when you put forth an idea, and this taps into evidence-based again, we embrace all kinds of ideas, from frontline people, right to our senior management ... when you're going tocome to the table with a great idea, come to the table with the research that supports why you're articulating this." 


\section{Training Time and Costs}

A second theme that emerged through our analysis revolved around training efficiencies. Training represents a significant cost for police organizations at an estimated $\$ 1$ billion Canadian per year (Goudge, Beare, Dupont et al, 2014) and much of the investment in police training is on meeting operational requirements rather than on specialized skill development (Johnson, Packham, Stonach et al., 2007). Given the costs and burdens associated with increasing training requirements, it would therefore be highly beneficial for police services to attract potential candidates who are already familiar with many of the specialized topics in policing.

Although not a major theme of discussions, a few of those senior officers $(n=3)$ and recruiters $(n=2)$ interviewed for our project saw a need for the introduction of the 'big topics' identified at the pre-recruit level. They believed that such previous knowledge would not only improve the quality of recruits, but would also reduce later training and educational costs. To illustrate, a senior officer commented that, "The most important thing for us... is for somebody to have good analytical skills, good problem-solving skills. We'll teach you how to be a police officer... You have to come with those other skills." These officers also agreed that there was not enough time available for recruits at the police college to be able to completely grasp the complexities of all, if not many, of the current topics in policing. They believed that the introduction of such concepts and topics at the pre-recruit level would not only set the course for their future career, but would also prove beneficial in saving both training costs and time at Police College.

To be clear, it was also recognized that, whereas reliance on police colleges and related training programs to inculcate knowledge of the array of policing concepts and models-including those discussed here-was not always practicable or financially feasible, the current system of postsecondary education in the province was not sufficiently standardized to ensure that ILP, EBP or POP models, among others, would be taught in each program or consistently within or across programs. One senior officer, in particular, stressed the need for a standardized curriculum at the college and university levels to provide a comparable level of understanding of such concepts across all potential groups of recruits. As our own previous research shows (Huey, Kalyal, \& Peladeau, 2017), there is no such content uniformity across various criminology and related programs. It is entirely likely that a potential recruit might graduate from a college- and/or university-based program with minimal knowledge of community policing, and little to no knowledge of intelligence-led, evidence-based and/or problem-oriented policing models.

\section{DISCUSSION \& CONCLUSIONS}

This exploratory paper drew upon a larger dataset on the educational needs assessment for future police recruits in Canada. We sought to explore whether police leaders and recruiters believed that education related to the current 'big topics' in policing was beneficial for incoming recruits. Based on 33 in-depth interviews, data analysis revealed two themes highlighting the importance of knowledge about these topics to policing and the benefits that agencies could derive from pre-recruitment education on these and other important concepts and ideas within policing.

Emerging from a consensus by senior officers and recruiters, the first theme suggested that a knowledge of the 'big topics' can help prepare recruits for both current shifts and the evolving future of the profession. Policing is no longer solely based on reactive strategies, and the transition from traditional to proactive model of policing requires a strong commitment to research, exercise of judgment, and the implementation of effective performance measures. Therefore, receiving education of such models as problemoriented policing can set the course for a recruit's future career. The same theme highlighted the importance of the big topics in policing in developing future recruits who are well aware of the demands of the profession. The dynamic nature of the policing environment requires individuals equipped with the skills and ability to continuously learn and adapt to shifting demands (Lucas 2002). Therefore, having knowledge of the 'big topics' is likely to help develop the capacity among new recruits to act as change agents in order to improve the practice of policing (Neyroud, 2011). Not only will they be able to challenge the elements of police culture that maintain status quo, but they will also be more likely to appreciate and implement these ideas more effectively through further in-service training.

The second theme related to savings in training time and costs as a result of hiring recruits who were already aware of important topics within policing. Post-entry training programs for police recruits entail focused professional training that is extremely intensive, often leaving little time for teaching topics that require critical thinking and assimilation of knowledge (Christopher, 2015). Given the high expenditure on training, and increasing budget constraints, it would be beneficial for police organizations to rely on educational institutions for imparting knowledge that should ideally be delivered incrementally over a greater span of time in order to be more effective.

The present study has a few limitations, owing to its exploratory nature. Firstly, the sample size, as well as geographical limitation, prevents us from drawing generalizable conclusions from our study. Future studies would benefit from a larger sample from agencies across Canada. Secondly, we did not test the participants on their own knowledge of the "big topics" in the interviews, which should also be addressed in future studies. Finally, as we had not included new recruits in our study, future researchers could draw a comparison between new recruits with and without prior education on the "big topics" in order to assess the difference in performance and attitudes towards police work.

Although preliminary in nature, the present study has important implications for police organizations. Given the relative importance placed on the 'big topics' of policing by senior police leaders and the increased use of these models within the policing environment, it is recommended that police organizations focus attention on (a) working with those colleges and universities willing to explore the possibility of shaping aspects of course curricula in ways that can be mutually beneficial (for not only agencies, but also for their students), and; (b) consider focusing on attracting and recruiting those individuals who possess not only skills, values, and attitudes deemed desirable, but also those educated 
in concepts such as intelligence-led, evidence-based and/or problem-oriented policing.

\section{ACKNOWLEDGMENTS}

This research has been funded by the Government of Ontario through the Ontario Human Capital Research and Innovation Fund.

\section{CONFLICT OF INTEREST DISCLOSURES}

The authors declare that there are no conflicts of interest.

\section{AUTHOR AFFILIATIONS}

*Department of Sociology, University of Western Ontario, London, ON, Canada.

\section{REFERENCES}

Braun, V. \& Clarke, V. (2006). Using thematic analysis in psychology. Qualitative Research in Psychology, 3(2): 77-101.

Christopher, S. (2015). The quantum leap: Police recruit training and the case for mandating higher education pre-entry schemes. Policing, 99(4): 388-404
Goudge, S., Beare, M., Dupont, B., Duxbury, L., Huey, L., Mackenzie, I.. ... Waller, I. (2014). Policing Canada in the 21st century: New policing for new challenges/The expert Panel on the Future of Canadian Policing Models. Ottawa, ON: Council of Canadian Academies. Available at: http://www.scienceadvice.ca/uploads/eng/assessments\%20 and\%20publications\%20and\%20news\%20releases/policing/policing_ fullreporten.pdf

Huey, L., Kalyal, H. \& Peladeau, H. (2017). Preparing police recruits of the future: An educational needs assessment. Full report provided to the Ontario Ministry of Advanced Education and Skills Development. London, ON: Western University. Available at: www.can-sebp.net and http:// ir.lib.uwo.ca/sociologypub/37/

Johnson, P., Packham, R., Stronach, S., \& Sissons, D. (2007). A national diagnostic on human resources in policing. Ottawa (ON): Hay Group and Police Sector Council.

Lucas, B. (2002). Power Up Your Mind. London, UK: Nicholas Brealey Publishing.

Neyroud, P. (2011). Review of Police Leadership and Training. London, UK HMSO 